\title{
The changing contribution of smoking to educational differences in life expectancy: indirect estimates for Finnish men and women from 1971 to 2010
}

\author{
Prof Pekka Martikainen ${ }^{1}$, Jessica $\mathrm{Ho}^{2}$ [Graduate student], Prof Samuel Preston ${ }^{2}$, and Prof \\ Irma T Elo² \\ Pekka Martikainen: pekka.martikainen@helsinki.fi \\ ${ }^{1}$ Population Research Unit, Department of Social Research, University of Helsinki, P.O. Box 18, \\ FIN-00014 University of Helsinki, Finland, tel: +358-9-191 23889; fax:+358-9-191 23967 \\ ${ }^{2}$ Population Studies Center, University of Pennsylvania, 3718 Locust Walk Philadelphia, PA \\ 19104, USA
}

\section{Abstract}

Background-We estimate the contribution of smoking to educational differences in mortality and life expectancy between 1971 and 2010 in Finland.

Methods-Eight prospective datasets with baseline in 1970, 1975, 1980, 1985, 1990, 1995, 2000 and 2005 and each linked to a 5-year mortality follow-up were used. We calculate life expectancy at age 50 with and without smoking-attributable mortality by education and gender. Estimates of smoking-attributable mortality were based on an indirect method that used lung cancer mortality as a proxy for the impact of smoking on mortality from all other causes.

Results-Smoking-attributable deaths constituted about $27 \%$ of all male deaths above age 50 in the early 1970s and $17 \%$ in the period 2006-2010; these figures were $1 \%$ and $4 \%$ among women, respectively. The life expectancy differential between men with basic versus high education increased from 3.4 to 4.7 years between 1971-75 and 2006-10. In the absence of smoking, these differences would have been 1.5 and 3.4 years, 1.9 years (55\%) and 1.3 years (29\%) less than those observed. Among women, educational differentials in life expectancy between the most and least educated increased from 2.5 to 3.0 years. This widening was nearly entirely accounted for by the increasing impact of smoking. Among women the contribution of smoking to educational differences had increased from being negligible in 1971-75 to $16 \%$ in 2006-2010.

Conclusions-Among men, the increase in educational differences in mortality in the past decades was driven by factors other than smoking. However, smoking continues to have a major influence on educational differences in mortality among men and its contribution is increasing among women.

\section{Keywords}

social inequalities; social epidemiology; mortality; smoking; lung cancer

\section{Conflict of Interest: None declared}

Ethics approval: We are grateful to the Statistics Finland for making the data available to us. The study has been approved by the ethics committee of the data provider.

Licence for Publication: The Corresponding Author has the right to grant on behalf of all authors and does grant on behalf of all authors, an exclusive licence (or non exclusive for government employees) on a worldwide basis to the BMJ Publishing Group Ltd to permit this article (if accepted) to be published in JECH and any other BMJPGL products and sublicences such use and exploit all subsidiary rights, as set out in our licence (http://group.bmj.com/products/journals/instructions-for-authors/licence-forms). 


\section{Introduction}

Major socioeconomic differences in mortality are observed in the United States and in Europe.[1-4] These mortality differentials translate into life expectancy differentials of 3-10 years between the extremes of the social hierarchy [5-6]. While smoking remains one of the major causes of mortality and morbidity in all Western countries, its contribution to social inequalities in mortality remains unclear and widely varying estimates have been presented. [7-17] These estimates are often based on select populations that are not representative of any national population, limited age ranges or for men only. Although large changes in cohort smoking histories have occurred in many countries, few previous studies focus on the contribution of smoking to changes in social differentials in mortality over time. Based on longitudinal data covering the total population of Finland with consistent measurement of educational attainment and mortality over time and no loss to follow-up, we present estimates of the contribution of smoking-attributable mortality to overall mortality differences by education for men and women at ages 50 and above for the period from 1971 to 2010. Our estimates are based on an indirect method developed by Preston, Glei and Wilmoth.[18-19]

\section{Data and Methods}

\section{Study population and mortality follow-up}

Our data consist of eight datasets covering the entire Finnish population. The first dataset is based on the 1970 population census, which has been linked to death records in the intercensal period 1971-75 by Statistics Finland (ethics committee permission TK 53-576-04). The other datasets were constructed similarly by linking the 1975, 1980, 1985, 1990, 1995, 2000 and 2005 census records to death records in 1976-80, 1981-85, 1986-90, 1991-95, 1996-2000, 2001-2005 and 2006-2010, respectively. In each period we followed on average about 2.1 million persons and observed 59000 deaths. More than $99.5 \%$ of death records were linked to the decedent's census records. Persons migrating from Finland in any of the 5-year periods were excluded from the analysis. This study is restricted to those aged 50 years and over because smoking-attributable mortality becomes non-negligible at these ages and selective migration is unlikely to influence our results (only about $0.35 \%$ of Finns aged 50 years and over migrated in the period 2001-2005). These data are among the most complete and accurate available in any nation for studying social determinants of mortality and have been previously used in related studies.[3-6]

\section{Measurement of education}

Education was measured with the same classification at the time of each census. It was coded into three categories based on the highest completed educational degree: (1) basic education lasting 9 years or less, (2) secondary education lasting 10-12 years, and (3) tertiary education lasting $13+$ years. We use educational attainment as the basic measure of socioeconomic status because it is consistently measured and because its level is established early in life. As a result, the association between educational attainment and mortality is less susceptible to interpretive problems resulting from reverse causation. Analyses (not presented here) of differentials by occupation-based social class confirm the main pattern of the results reported in this paper.

\section{Methods}

We estimate the magnitude of smoking-attributable mortality by education in Finland using an indirect estimation method developed by Preston, Glei and Wilmoth.[18-19] The method is based on data from 21 high income countries for the period 1950 to 2007. The method 
uses age- and sex-specific lung cancer death rates as an indicator of the damage from smoking and introduces a regression model that uses lung cancer mortality to predict mortality from other causes of death. Finland is one of the countries in the database used to estimate the parameters of the model. The coefficients from this regression model and information on expected lung cancer death rates among non-smokers are used to estimate the overall fraction of deaths attributable to smoking. The method is restricted to ages 50 and above, ages at which most lung cancer deaths occur. Preston, Glei and Wilmoth demonstrate that the method produces results very similar to those obtained from an older widely used method developed by Peto and Lopez.[20] We use the coefficients published in Preston et al (Table 1)[19] to estimate smoking-attributable mortality by educational attainment. For additional methodological detail see the Appendix and the discussion section for evaluation of the underlying assumptions.

The results are presented in terms of proportions of deaths attributable to smoking at ages 50 and above, life expectancies at age 50, and age-adjusted death rates with and without smoking-attributable deaths. All analyses are performed separately for men and women as smoking patterns in Finland differ substantially by gender.

\section{Results}

In the early 1970s smoking-attributable deaths constituted about a quarter of all male deaths above age 50 and they reduced life expectancy by 3.0 years (Table 1 and Figure 1; 95\% CIs around the point estimates are very tight and we thus refrain from presenting them later for clarity of presentation). In the period 2006-2010 the proportion of deaths due to smoking had declined to less than $20 \%$, corresponding to a life expectancy reduction of about 1.7 years. During this same period, male life expectancy at age 50 increased from 22.0 years in the early 1970 s to 29.0 years in 2006-2010. Among women smoking-attributable deaths increased from less than $1 \%$ to $4 \%$ in the same period and they contributed to a loss of about 0.6 years in life expectancy by the late 2000s. Over the period from 1971-75 to 2006-2010 the mean age at death from lung cancer among men increased from about 67 to 75 years, while for all-cause mortality the increase was from 70 to 75 years. For women the corresponding figures were 64 to 75 years for lung cancer and 75 to 82 years for all-cause mortality (results not shown here).

Sharp educational differentials in smoking-attributable mortality were observed among men in the 1970s; $28 \%$ of all deaths among men with basic education were attributable to smoking compared to $14 \%$ among the most highly educated men. Life expectancy among the highly educated was 3.4 years greater than among those with the lowest level of schooling. We estimate that this difference would have been only 1.5 years in the absence of smoking, so that smoking accounted for 55\% of the educational gap in life expectancy in the early 1970s. In the period 2006-2010, smoking-attributable deaths had declined to about $20 \%$ among men with basic education and to $9 \%$ among the most highly educated men (Figure 1). By this time, the life expectancy gap between these two groups had grown to 4.7 years; without smoking it would have been about 3.4 years. Thus, the contribution of smoking to the educational difference in life expectancy declined from 1.9 years to 1.3 years whereas educational inequality in life expectancy at age 50 grew from 3.4 years to 4.7 years. Although smoking continued to make a substantial contribution, other influences were clearly emerging (Figure 2 and Table 1 ).

Among women smoking-attributable deaths were extremely rare in all educational groups in the 1970s and their contribution to educational differences in life expectancy was negligible (Figure 2). By the period 2006-2010, the contribution of smoking-attributable deaths to educational differences in female life expectancy at age 50 had increased to about 0.5 years 
whereas the total difference had increased from about 2.5 years in the early 1970 s to about 3.0 years (Table 1 ). We thus estimate that the increase in the life expectancy gap of 0.5 years among women between 1971-75 and 2006-10 is entirely attributable to smoking; when we remove the imprint of smoking, the educational difference in life expectancy remains constant at about 2.5 years over the entire period (Table 1 ).

In Table 2 changes in the contribution of smoking to educational differentials are presented in terms of age-adjusted mortality rates. For men aged 50-69 the contribution of smoking declined from $73 \%$ to $30 \%$ between 1971-75 and 2006-10. Among older men (aged 70+) the contribution increased slightly in the same period and in 2006-2010 was higher (47\%) than among younger men. For younger women (aged 50-69) the contribution of smoking to educational differentials in mortality increased from $1 \%$ to $32 \%$ between the two periods but remained relatively modest among older women.

Table 1 also shows that smoking has made a large contribution to sex differences in Finnish longevity and to changes therein. At age 50, women outlived men by 6.1 years in 1971-75 but that gap would have been only about half as large - 3.1 years - in the absence of smoking. Because women's smoking subsequently increased and men's decreased, changes in smoking behaviour helped to produce a narrowing of the sex gap in later years. By 2006-10, smoking-attributable mortality accounted for only about a fifth, or 1.1 years, of the 5.4-year sex gap in life expectancy.

\section{Discussion}

\section{Summary of the main results}

This is the first study in any nation to quantify the contribution of smoking to educational differences in mortality and life expectancy over time. We show that smoking has left a large but diminishing imprint on life expectancy at age 50 among Finnish men and made a small but increasing contribution among Finnish women. We observe that at age 50, life expectancy differentials between men with basic education and the most highly educated men increased considerably between 1971-75 and 2006-2010. At the same time, the contribution of smoking to these differentials declined substantially. Among women the contribution of smoking to educational differentials increased over the same period but remained moderate. However, among women aged 50-69 the contribution of smoking to mortality differentials has increased dramatically.

\section{Strengths and weaknesses}

Compared to observational cohort studies that rely on self-reported measures of smoking status at a single point in time, the indirect method employed here avoids difficulties in accurately measuring individual life-time smoking exposure due to recall bias, preferential reporting, individual variability in smoking intensity (e.g., inhalation), exposure to passive smoking, as well as single measurement in time and loss to follow-up. In Finland, for example, nationally representative postal surveys give a substantially lower estimate of the level of tobacco consumption as compared to sales statistics. Our calculations (not presented here) based on the 2001 national sales statistics for Finland [21] covering taxable cigarettes and cigars, pipe and self-rolled cigarette tobacco as well estimates of tax-free cigarettes from travel abroad indicate that Finns smoked on average about 1500 cigarette equivalents for every Finn aged 15 years and over. Individual-level survey responses in 2001[21,22] — with an average response rate of about $75 \%$ - to questions about current smoking and the number of tobacco products consumed, however, imply that only about 1140 cigarettes per capita were smoked annually. The bias is most likely even greater for lifetime exposure to smoking. 
Our estimates may be vulnerable to possible data limitations or model assumptions that affect the overall level or educational differences in smoking-attributable mortality. With regard to the overall level of smoking-attributable mortality our estimates are not, however, affected by changes in coding practices of lung cancer deaths, because we used a harmonized cause of death data file and coding changes for lung cancer deaths were minor during the period considered. More importantly, the Preston model assumes the same relationship between smoking and lung cancer mortality in all countries used to estimate the coefficients. This assumption may be unreasonable if lung cancer deaths among nonsmokers caused by factors other than smoking vary between countries. Thus, in a population where factors other than smoking had a substantial impact on lung cancer mortality, the assumed lung cancer death rates among non-smokers would be too low and the method would overestimate the overall contribution of smoking. This scenario is unlikely in Finland, and alternative calculations that assume 50\% higher lung cancer mortality among nonsmokers leave the basic patterns of results unaltered. Furthermore, our sex-specific estimates of smoking-attributable mortality for Finland are similar to those obtained using different methods. The estimates are, for example, broadly consistent with previous estimates based on the Peto-Lopez method and slightly lower than estimates based on cause of death specific population attributable fractions and estimates of smoking prevalence by Martelin et al. $[20,23]$ giving credibility to the model assumptions, coefficients and estimates produced by the current method.

We further assume that the model coefficients characterizing the relationship between lung cancer mortality and mortality from all other causes and lung cancer death rates among nonsmokers do not differ by level of education. We assessed the sensitivity of our results to this assumption by assuming 50\% higher lung cancer mortality among non-smokers in the lowest education group than in the highest group; e.g. because of higher occupational exposure to asbestos among those with lowest level of education. We found that the contribution of smoking to educational differentials in life expectancy would have been reduced by only about $3 \%$ in the most recent period. Furthermore, in evaluating the contribution of smoking to mortality differentials between US immigrants and native-born Americans Blue and Fenelon reached similar conclusions regarding the applicability of this method to different population subgroups.[24] They found that the method produced robust results when they relaxed the assumption of similar lung cancer death rates among nonsmokers across various sub-populations. Thus, our estimates of the contribution of smoking to educational differences in mortality are robust and we are confident in our main findings.

\section{Comparisons to previous research and interpretation}

Prior literature contains a range of estimates regarding the contribution of smoking to social inequalities in mortality. Variation among estimates stems from both methodological and substantive sources. Typically the estimates are based on either direct regression-based methods using data from observational cohort studies or indirect methods based on aggregate data. In cohort studies, regression-based measures of association (e.g., hazard ratios) between the highest and lowest social groups are adjusted for observed smoking behaviour. In such studies the attenuation of this association after adjustment is interpreted as the contribution of smoking. These estimates show the reduction in the relative social differences in mortality under the assumption of no social differences in smoking exposure at a level of overall smoking exposure defined by the observed smoking variables. On the other hand, estimates based on indirect methods usually provide an estimate of the contribution of smoking - often presented in terms of rate differences or here also in terms of life expectancy differences - under a hypothetical scenario in which a population and all its social strata have no exposure to smoking. To provide an alternative to this assumption, we carried out additional calculations that left smoking-attributable mortality untouched in 
the higher educated group but reduced smoking-attributable deaths in all other educational groups so that the fraction of all deaths due to smoking was the same as that observed among the most highly educated. With these assumptions the contribution of smoking to overall male life expectancy in 2001-2005 was similar to but less than if smoking were eliminated entirely; educational differentials would have been $26 \%$ less instead of $29 \%$ less with the complete eradication of smoking.

Bearing these methodological differences in mind - and concentrating on the results that assume smoking eradication - we find a somewhat smaller contribution of smoking to educational differences in mortality among men below age 70 than do Jha at al. for England and Wales, USA, Canada and Poland based on the Peto-Lopez method and on data from the mid-1990s.[15] Our estimates for the contribution of smoking at these ages is about $40 \%$ during this period while Jha et al estimate a contribution of about 50-60\%. National differences in the timing of the smoking epidemic partly account for the different time patterns of smoking-attributable deaths. Results from Preston et al.[18,19] as well as results in Table 1 indicate that overall smoking-attributable mortality has declined rapidly in Finland since the 1980s whereas progress has been less favourable in USA, Canada and UK. Differences in age coverage are also likely to affect the estimated impact of smoking. The Jha et al. study stops at age 70 while ours extends to the highest ages. A comparative study by Mackenbach et al. [25] of ten European populations in the early 1990s - also relying on an indirect method - provides estimates that are consistent with but somewhat lower than ours for Finland and Jha et al.'s for UK. This difference is most likely due to Mackenbach et al. using a cruder educational classification that divides the population into only two categories. However, it is noteworthy that although smoking rates are high in many Southern European countries, until recently social differentials in smoking have remained relatively small. Smoking thus continues to make a major contribution to male life expectancy in these countries but its contribution to social differentials is modest.

\section{Implications and future research}

The smoking history of Finnish men - typical of many other Northern European and AngloSaxon countries - is characterized by high levels of ever regular smoking among men born before the Second World War. Smoking prevalence peaked with the 1911-25 birth cohort and declined thereafter due mainly to a decline in smoking initiation. Among women smoking has increased in successive birth cohorts because of increasing initiation.[26,27] At the same time smoking cessation has increased with no apparent cohort trend.[27] The convergence of gender differences in smoking has been associated with changes in women's social position beginning in the 1960s, [27] but it may also be linked to diffusion of smoking, with smoking habits among women becoming more similar to those of men in nations with a long history of smoking.[28] Antismoking activities began in Finland in the mid-1960s and the passing of the Tobacco Control Act of 1976 prohibited smoking in public places, restricted advertising, set a 16 year age limit for purchase of tobacco products and introduced health warnings on packages. After substantial tobacco price increases in the mid-1970s subsequent real price increases have been more modest. The 1976 Act most likely made a significant contribution to declines in smoking among men and capped the increasing trend among women.[26] Finland has also had large and long-lasting social differentials in smoking that have increased in the past three decades. This increase is due to a rapid decline in smoking in the higher social groups that is not matched in other groups among men and to the increasing prevalence of smoking in the lowest social strata among women. It has been suggested that persistent smoking among women in the lowest social groups is associated with the particularly harsh material conditions of life combined with excessive household and caretaking obligations.[29,30] 
Our estimates of levels of and trends in smoking-attributable mortality by education and gender are consistent with these smoking patterns. Among men the sizable contribution of smoking to total mortality and to educational differentials in mortality in the 1970s, and their subsequent decline, are consistent with trends in smoking behaviour by social position among men. In many countries, declining smoking rates among more recent birth cohorts imply that as younger men age, the contribution of smoking to life expectancy reductions and life expectancy differentials is likely to continue to diminish. However, our results show that educational differentials in life expectancy would have grown even without smoking, from 1.5 to 3.4 years over the study period. Future research should aim to quantify the contribution of other risk factors, such as heavy drinking and increasing rates of obesity, to increasing mortality differentials.

Because of the later onset of smoking among women in most countries, much of the evidence on the contribution of smoking to mortality and particularly mortality differentials has focused on men. However, more research on women is sorely needed. Our results show that the current overall contribution of smoking to educational differentials is moderate (roughly 16\% above age 50) among Finnish women, but it has already reached 32\% among women between ages 50 and 70 . Smoking also fully explains increasing educational differentials in life expectancy among women. As younger cohorts of women with higher levels of smoking and sharper educational gradients in smoking replace older cohorts of women, we may see slower life expectancy increases and increasing educational differentials in mortality among women in the future.

\section{Supplementary Material}

Refer to Web version on PubMed Central for supplementary material.

\section{Acknowledgments}

The authors thank Riina Peltonen and Valentina Ponomarenko for help with calculations and setting up the tables and figures and Arun Hendi for guidance in calculating confidence intervals.

Funding: This study was supported by the Academy of Finland, National Institutes of Eunice Kennedy Shriver National Institute of Child Health and Development Population Research Infrastructure Program R24 HD-044964 at the University of Pennsylvania and the National Science Foundation Graduate Research Fellowship under Grant No. DGE-0822. The study sponsors had no role in the design or conduct of the study; the collection, management, analysis, and interpretation of the data; or the preparation, review, or approval of the manuscript.

\section{Appendix}

The new indirect method to estimate smoking-attributable mortality is fully developed by Preston, Glei and Wilmoth in their 2010 paper $[18,19]$ and relies on the strength of the relationship between cigarette smoking and lung cancer mortality. Lung cancer mortality acts as a proxy for damage from smoking and is used to estimate the impact of smoking on mortality from all other causes of death. The high proportion of lung cancer deaths that are attributable to smoking, along with evidence that changes in lung cancer risk result primarily from the history of smoking behavior, supports the validity of this assumption.[18]

In the first stage of the indirect estimation method, age-, sex- and year-specific lung cancer death rates are used to predict age-sex-year-specific mortality from all other causes of death. Controls for country fixed effects, age and time dummies, as well as interactions between country and year, lung cancer mortality and year and lung cancer mortality and age are included. The coefficients from this model (in this paper we use the coefficients published in Preston et al (Table 1)[19]), along with estimates of the expected lung cancer death rate among non-smokers (in high income countries typically associated with passive smoking 
and radon exposure), are then used to estimate the overall fraction of deaths attributable to smoking. Preston, Glei and Wilmoth estimated this model using data from 21 developed countries for the period 1950 through 2007. They have demonstrated that the results produced are very similar to estimates produced using the Peto-Lopez method.[18]

As a check for model validity, Preston, Glei and Wilmoth predicted mortality from four groups of causes using lung cancer mortality. As expected, strong relationships were observed between lung cancer mortality and both smoking-related cancers and respiratory diseases, while a weak relationship was observed between lung cancer mortality and external causes (accidents, homicide and suicide), a category for which smoking should be unrelated to mortality. The authors also assessed the robustness of the results to alternative model specifications.[18]

To apply this method, we first estimate the fraction of deaths due to lung cancer in a specific sex-age-education group that is attributable to smoking, $A_{L}$, as follows:

$$
A_{L}=\frac{M_{L}-\lambda_{L}^{N}}{M_{L}}
$$

where $M_{L}$ is the observed sex-age-education-specific lung cancer death rate and $\lambda_{L}^{N}$ is the expected sex- and age-specific lung cancer death rate among non-smokers, which is taken from the Cancer Prevention Study II (CPS-II). These rates are similar to death rates from lung cancer observed among non-smokers in other industrialized countries. [18]

Second, we estimate the fraction of deaths from all other causes besides lung cancer in a specific sex-age-education group that is attributable to smoking, $A_{0}$, as follows:

$$
A_{0}=1-e^{-\beta_{L}\left(M_{L}-\lambda_{L}^{N}\right)}
$$

where $\beta_{L}$ are the age- and sex-specific model coefficients published in Preston, Glei and Wilmoth and $M_{L}$ and $\lambda_{L}^{N}$ are as defined above. [19] In cases where $M_{L}-\lambda_{L}^{N}$ is negative, the fraction of deaths attributable to smoking is set to 0 .

The overall attributable fraction of deaths from all causes that is due to smoking, $A$, is then calculated as:

$$
A=\frac{A_{L} D_{L}+A_{0} D_{0}}{D}
$$

for each sex-age-education group, where $D_{L}$ is the observed number of deaths from lung cancer, $D_{o}$ is the observed number of deaths from all other causes, and $D$ is the observed number of deaths from all causes combined. Thus, the fraction of all deaths above age 50 that is attributable to smoking, $A_{50+}$, is:

$$
A_{50+}=\frac{\sum_{i=50-54}^{85+} A_{i} D_{i}}{\sum_{i=50-54}^{85+} D_{i}}=\frac{\sum_{i=50-54}^{85+} A_{i} D_{i}}{D_{50+}}
$$


95\% confidence intervals for the estimates of the smoking-attributable fractions are produced using the delta method. The variance estimates for $A_{50+}$ incorporate random variation in the observed death rates and variation in the estimated regression coefficients.

To translate smoking-attributable mortality by age into implications for life expectancy at age 50, we obtain adjusted age-specific death rates (i.e., death rates from which smokingattributable mortality is removed), $m_{i}^{-s}$, as follows:

$$
m_{i}^{-s}=m_{i}\left(1-A_{i}\right)
$$

where $t=50-54,55-59, \ldots, 80-84,85+$ and $m_{i}$ is the sex-age-education-specific death rate from all causes combined. We then use standard life table procedures to calculate life expectancy at age 50 by sex and education level with and without the inclusion of smokingattributable deaths to determine the extent to which smoking contributes to educational differentials in life expectancy at age 50 and whether this contribution has changed over time.

The central assumption of this model is that lung cancer mortality accurately proxies the impact of smoking damage on mortality from other causes. This method may be less reliable in populations in which factors other than smoking have a strong impact on lung cancer mortality, such as air pollution in China, or in developing country contexts.[18] See discussion for a more detailed evaluation of model assumptions as they relate to the context of this study.

\section{References}

1. Mackenbach JP, Stirbu I, Roskam AJ, et al. Socioeconomic inequalities in health in 22 European countries. N Engl J Med. 2008; 358:2468-81. [PubMed: 18525043]

2. Elo IT. Social class differentials in health and mortality: patterns and explanations in comparative perspective. Annu Rev Sociol. 2009; 35:553-72.

3. Martikainen P, Valkonen T, Moustgaard H. The effects of individual taxable income, household taxable income, and household disposable income on mortality in Finland, 1998-2004. Popul Stud. 2009; 63:147-62.

4. Martikainen P, Blomgren J, Valkonen T. Change in the total and independent effects of education and occupational social class on mortality: analyses of all Finnish men and women in the period 1971-2000. J Epidemiol Community Health. 2007; 61:499-505. [PubMed: 17496258]

5. Elo IT, Martikainen P, Smith KP. Socioeconomic differentials in mortality in Finland and the United States: the role of education and income. Eur J Popul. 2006; 22:179-203.

6. Tarkiainen L, Martikainen P, Laaksonen M, et al. Trends in life expectancy by income from 1988 to 2007: decomposition by age and cause of death. J Epidemiol Community Health. 2012; 66:573-8. [PubMed: 21378391]

7. Pekkanen J, Tuomilehto J, Uutela A, et al. Social class, health behaviour, and mortality among men and women in eastern Finland. BMJ. 1995; 311:589-93. [PubMed: 7663252]

8. Laaksonen M, Talala K, Martelin T, et al. Health behaviours as explanations for educational level differences in cardiovascular and all-cause mortality: a follow-up of 60000 men and women over 23 years. Eur J Public Health. 2008; 18:38-43. [PubMed: 17569702]

9. Khang YH, Lynch JW, Yang S, et al. The contribution of material, psychosocial, and behavioral factors in explaining educational and occupational mortality inequalities in a nationally representative sample of South Koreans: relative and absolute perspectives. Soc Sci Med. 2009; 68:858-66. [PubMed: 19121885]

10. Woodward M, Oliphant J, Lowe G, et al. Contribution of contemporaneous risk factors to social inequality in coronary heart disease and all causes mortality. Prev Med. 2003; 36:561-8. [PubMed: 12689801] 
11. van Oort FV, van Lenthe FJ, Mackenbach JP. Material, psychosocial, and behavioural factors in the explanation of educational inequalities in mortality in The Netherlands. J Epidemiol Community Health. 2005; 59:214-20. [PubMed: 15710599]

12. Schrijvers CT, Stronks K, van de Mheen HD, et al. Explaining educational differences in mortality: the role of behavioral and material factors. Am J Public Health. 1999; 89:535-40. [PubMed: 10191797]

13. Lynch JW, Kaplan GA, Cohen RD, et al. Do cardiovascular risk factors explain the relation between socioeconomic status, risk of all-cause mortality, cardiovascular mortality, and acute myocardial infarction? Am J Epidemiol. 1996; 144:934-42. [PubMed: 8916504]

14. Lantz PM, House JS, Lepkowski JM, et al. Socioeconomic factors, health behaviors, and mortality: results from a nationally representative prospective study of US adults. JAMA. 1998; 279:1703-8. [PubMed: 9624022]

15. Jha P, Peto R, Zatonski W, et al. Social inequalities in male mortality, and in male mortality from smoking: indirect estimation from national death rates in England and Wales, Poland, and North America. Lancet. 2006; 368:367-70. [PubMed: 16876664]

16. Blakely $\mathrm{T}$, Wilson $\mathrm{N}$. The contribution of smoking to inequalities in mortality by education varies over time and by sex: two national cohort studies, 1981-84 and 1996-99. Int J Epidemiol. 2005; 34:1054-62. [PubMed: 16109733]

17. Meara ER, Richards S, Cutler DM. The gap gets bigger: changes in mortality and life expectancy, by education, 1981-2000. Health Aff. 2008; 27:350-60.

18. Preston SH, Glei DA, Wilmoth JR. A new method for estimating smoking-attributable mortality in high-income countries. Int J Epidemiol. 2010; 39:430-8. [PubMed: 20032265]

19. Preston, SH.; Glei, DA.; Wilmoth, JR. Contribution of smoking to international differences in life expectancy. In: Crimmins, EM.; Preston, SH.; Cohen, B., editors. International Differences in Mortality at Older Ages Dimensions and Sources. Washington, DC: The National Academies Press; 2010. p. 105-131.

20. Peto R, Lopez AD, Boreham J, et al. Mortality from tobacco in developed countries: indirect estimation from national vital statistics. Lancet. 1992; 339:1268-78. [PubMed: 1349675]

21. Official Statistics of Finland. Tobacco statistics 2009. Helsinki: Statistics Finland; 2009. www.stat.fi/til/tup/2009/tup_2009_2010-12-22_fi.pdf [accessed July 2012]

22. Helakorpi, S.; Patja, K.; Prättälä, R., et al. Health Behaviour and Health among Finnish Adult Population, Spring 2001. Helsinki: National Public Health Institute; 2001. www.ktl.fi/ publications/2001/b16.pdf [accessed July 2012]

23. Martelin T, Mäkelä P, Valkonen T. Contribution of deaths related to alcohol or smoking to the gender difference in life expectancy: Finland in the early 1990s. Eur J Public Health. 2004; 14:422-7. [PubMed: 15542881]

24. Blue L, Fenelon A. Explaining low mortality among US immigrants relative to native-born Americans: the role of smoking. Int J Epidemiol. 2011; 40:786-93. [PubMed: 21324939]

25. Mackenbach JP, Huisman M, Andersen O, et al. Inequalities in lung cancer mortality by the educational level in 10 European populations. Eur J Cancer. 2004; 40:126-35. [PubMed: 14687796]

26. Helakorpi S, Martelin T, Torppa J, et al. Impact of the 1976 Tobacco Control Act in Finland on the proportion of ever daily smokers by socioeconomic status. Prev Med. 2008; 46:340-5. [PubMed: 18158177]

27. Laaksonen M, Uutela A, Vartiainen E, et al. Development of smoking by birth cohort in the adult population in eastern Finland 1972-97. Tob Control. 1999; 8:161-8. [PubMed: 10478400]

28. Pampel FC. Cigarette diffusion and sex differences in smoking. J Health Soc Behav. 2001; 42:388-404. [PubMed: 11831139]

29. Graham H. Gender and class as dimensions of smoking behaviour in Britain: insights from a survey of mothers. Soc Sci Med. 1994; 38:691-8. [PubMed: 8171347]

30. Rahkonen O, Laaksonen M, Karvonen S. The contribution of lone parenthood and economic difficulties to smoking. Soc Sci Med. 2005; 61:211-6. [PubMed: 15847973] 


\section{What is Already Known on This Topic}

- Large and increasing social differences in mortality are observed in many high income countries

- Smoking-related mortality is known to vary by educational attainment

- Little is known about the contribution of smoking to educational differentials in mortality over time.

\section{What this Study Adds}

- Smoking has left a large but diminishing imprint on mortality and educational mortality differentials among men and made a small but increasing contribution among women

- Among men, educational differentials in life expectancy would have grown even without smoking

- Among women, ageing of the younger cohorts with higher prevalence of smoking is likely to contribute to increasing social inequalities in mortality in the coming decades 
Males

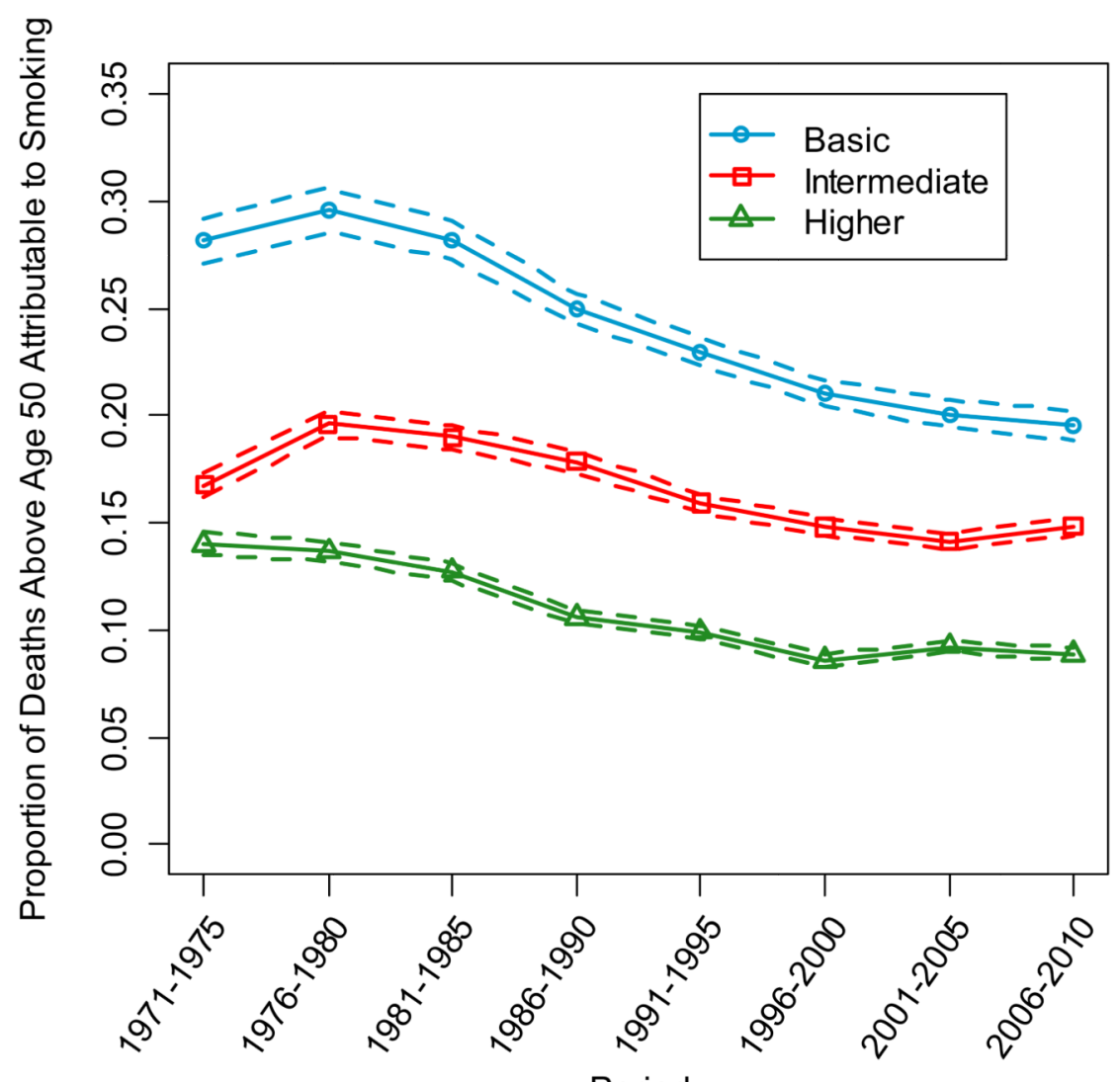

Period 
Females

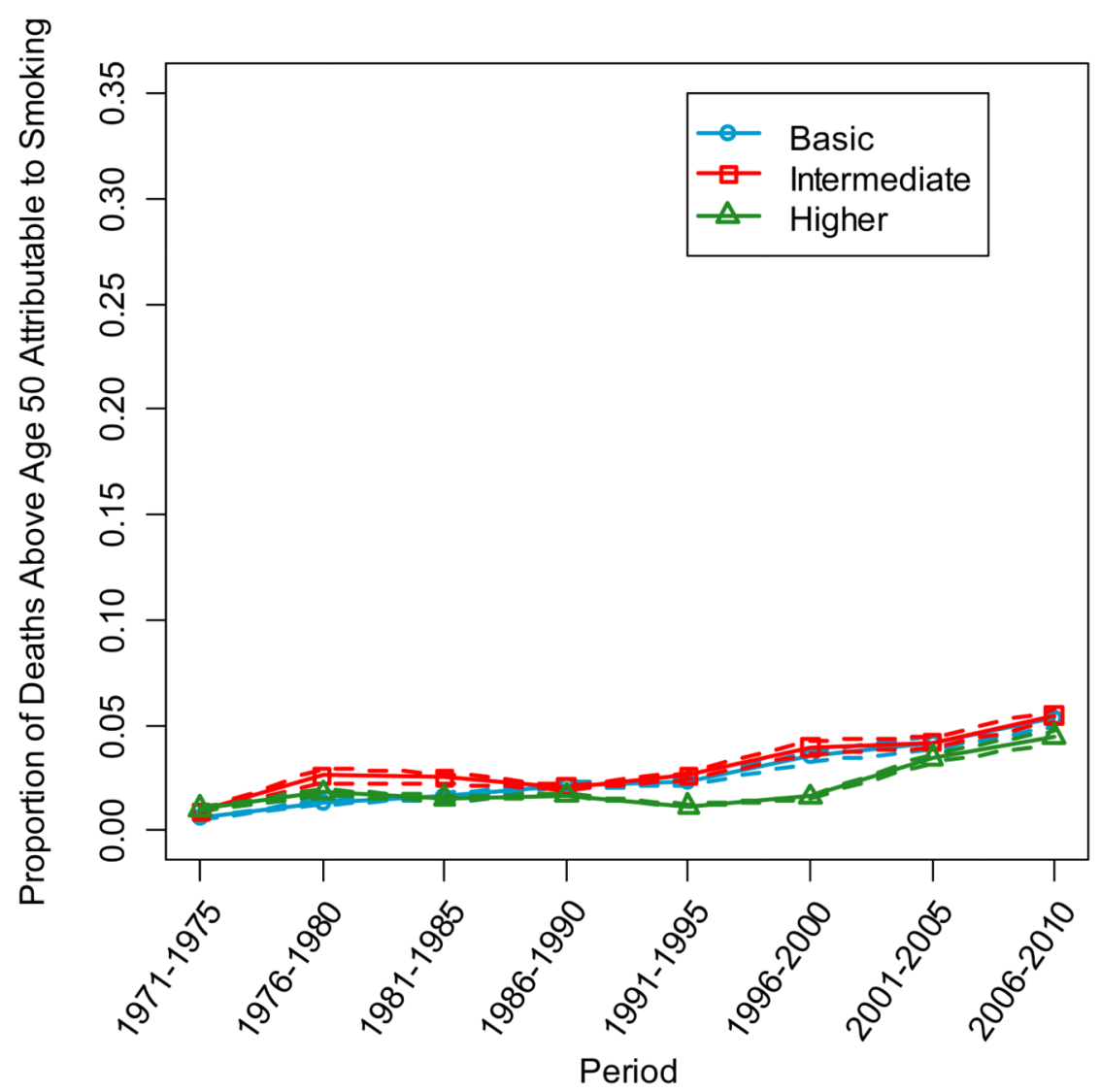

Figure 1.

Proportion of deaths above age 50 attributable to smoking. Finnish men (left panel) and women (right panel) aged 50 in 1971-2010. 
Males

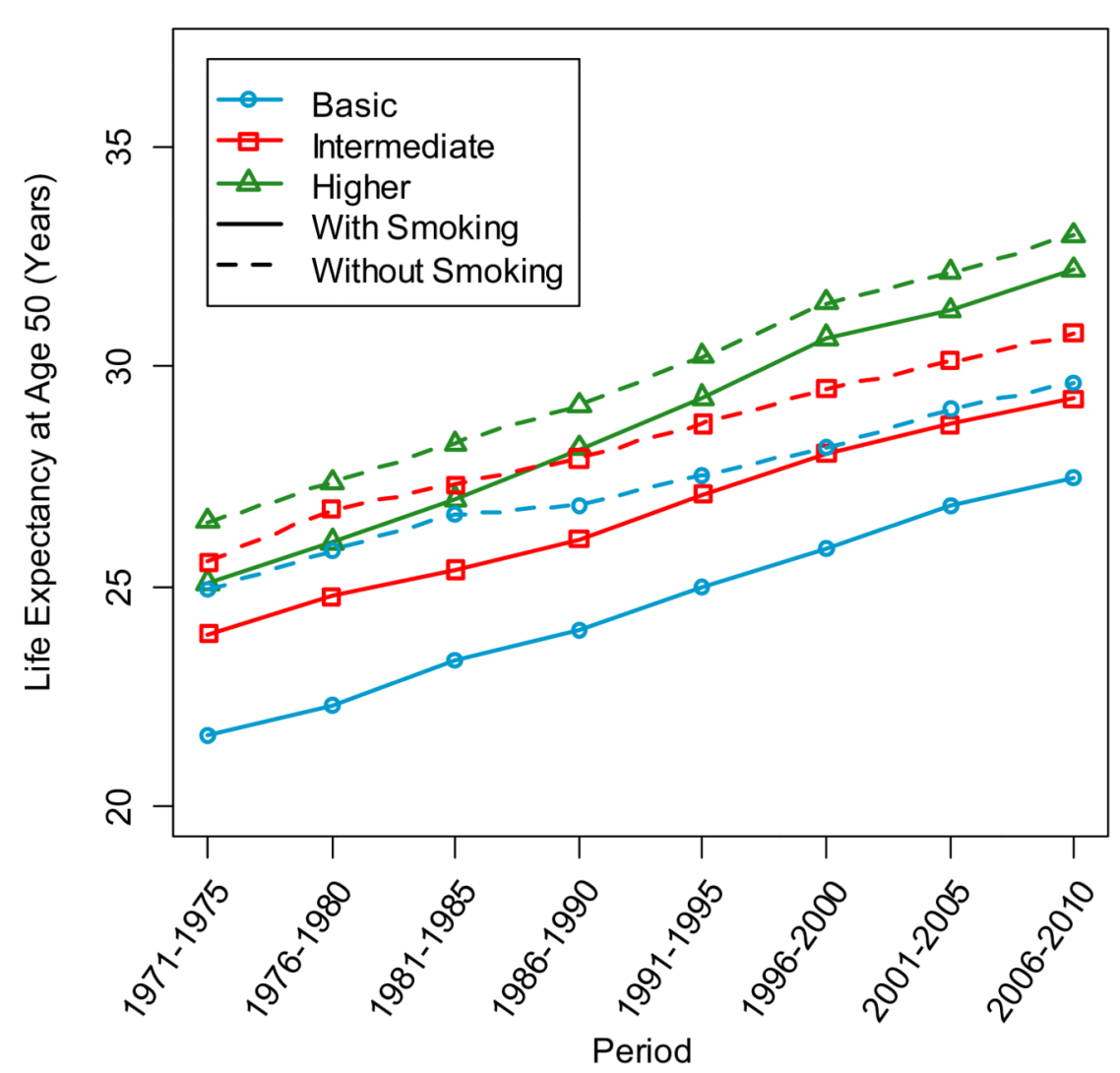

J Epidemiol Community Health. Author manuscript; available in PMC 2014 March 01. 
Females

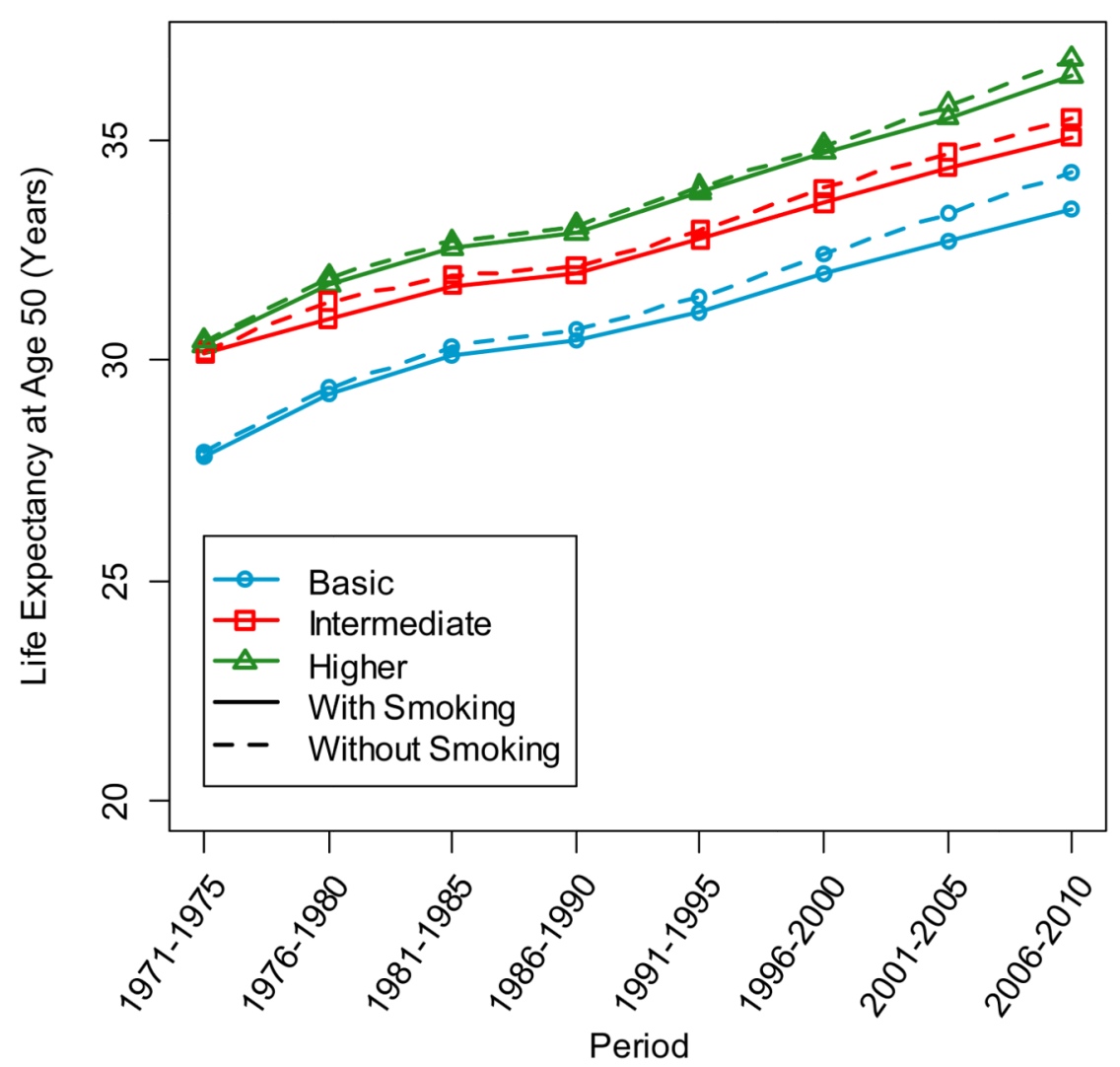

Figure 2.

Life expectancy by education with and without smoking. Finnish men (left panel) and women (right panel) aged 50 in 1971-2010. 


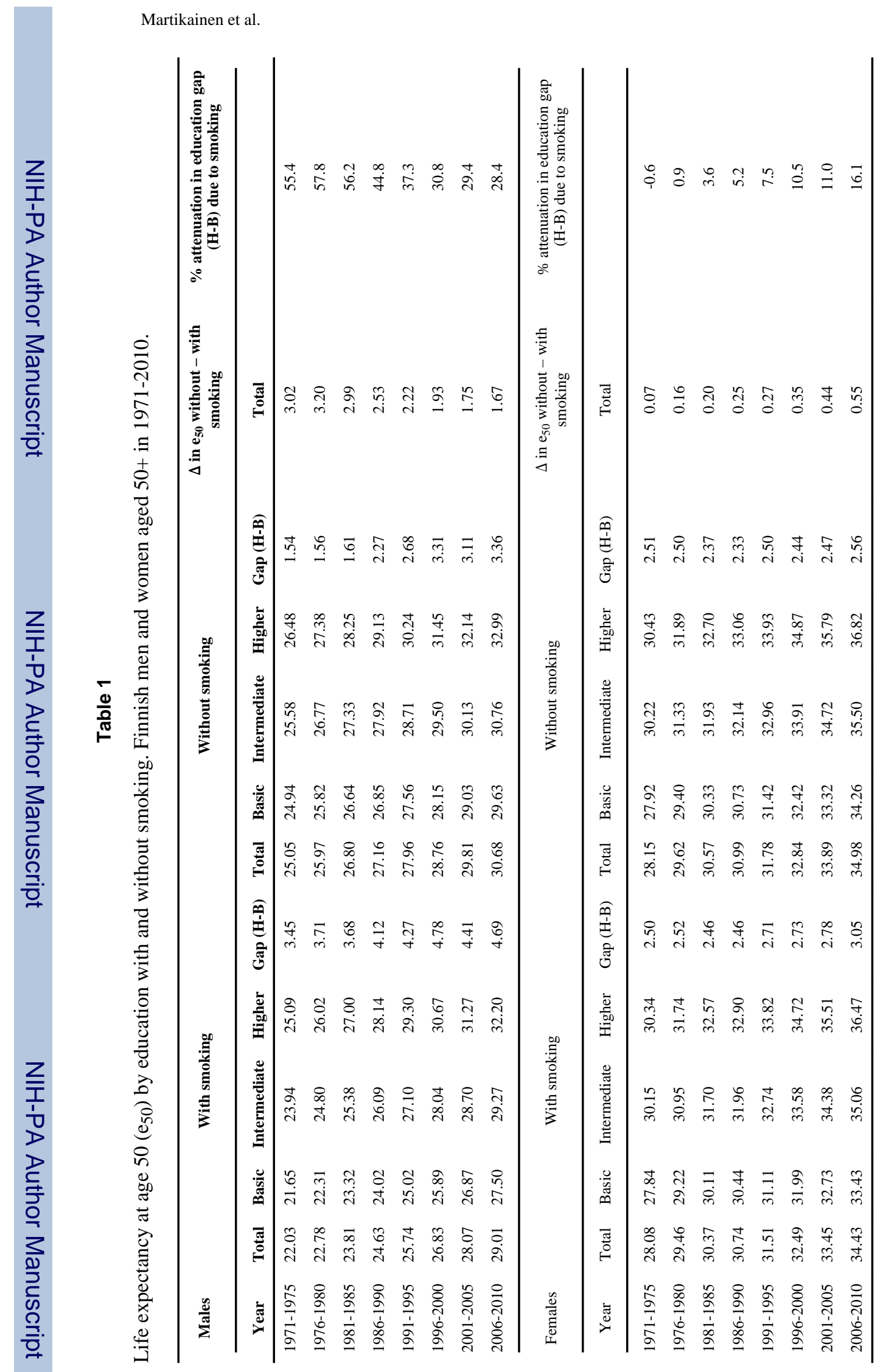


